\title{
A ESPIRITUALIDADE NO AMBIENTE DE TRABALHO COMO AGENTE DE AUTORREGULAÇÃO DO CAOS ORGANIZACIONAL
}

\author{
Wanderson Silva Damião ${ }^{1}$ \\ Erick Dawson de Oliveira ${ }^{2}$ \\ Elizangela Jesus Oliveira ${ }^{3}$ \\ Dagmar Silva Pinto de Castro ${ }^{4}$ \\ Valéria Rueda Elias Spers ${ }^{5}$
}

DAMIÃO, W. S; OLIVEIRA, E. D. de; OLIVEIRA, E. J; CASTRO, D. S. P; SPERS, V. R. E. A espiritualidade no ambiente de trabalho como agente de autorregulação do caos organizacional. Rev. Ciênc. Empres. UNIPAR, Umuarama, v. 18, n. 2, p. 229-240, jul./dez. 2017.

RESUMO: O presente estudo objetivou refletir como as organizações enquanto cérebros, segundo a metáfora de Morgan (2002), podem desenvolver a espiritualidade no ambiente de trabalho como um agente de autoregulação do caos organizacional contemporâneo. Considerando a necessidade contemporânea atual das organizações em buscarem soluções para a diminuição ou eliminação das dimensões destrutivas que a integram, o estudo se justifica como uma possível resposta a esse problema social. Para isso, desenvolveu-se um ensaio teórico utilizando como principais referências as menções teóricas de Morgan (2002) e Siqueira et al. (2014). Enquanto ensaio, o estudo não objetivou apresentar conclusões definitivas sobre o assunto, contudo, as observações indicam a possibilidade de a espiritualidade no ambiente de trabalho ser um instrumento de auto regulação do caos organizacional contemporâneo. Dessa forma, essa e outras questões apresentadas no estudo, encontram viabilidade para o desenvolvimento de futuras pesquisas empíricas para análise desse importante tema da atualidade. PALAVRAS-CHAVE: Ambiente de trabalho; Autoregulação; Caos organizacional; Espiritualidade.

\section{SPIRITUALITY IN THE WORKPLACE AS AUTO AGENT ORGANIZATIONAL REGULATION OF CHAOS}

\footnotetext{
DOI: $10.25110 /$ receu.v18i 2.6256

${ }^{1}$ Doutorando em Administração Unimep - SP

${ }^{2}$ Doutorando em Administração Unimep - SP

${ }^{3}$ Doutoranda em Administração Unimep - SP

${ }^{4}$ Professora Doutora - PPGA - Unimep - SP

${ }^{5}$ Professora Doutora - PPGA - Unimep - SP
}

ABSTRACT: The present study aimed to reflect how organizations as brains, 
according to the metaphor of Morgan (2002), can develop spirituality in the workplace as an agent of self-regulation of contemporary organizational chaos. Considering the contemporary need of organizations to seek solutions for the reduction or elimination of the destructive dimensions that integrate it, the study is justified as a possible response to this social problem. For this, a theoretical essay was developed using as main references the theoretical references of Morgan (2002) and Siqueira et al. (2014). While testing, the study did not aim to present definitive conclusions on the matter, however, the observations indicate the possibility of spirituality in the workplace as a tool of self regulation of contemporary organizational chaos. Thus, this and other questions presented in the study, find feasibility for the development of future empirical research to analyze this reflection.

KEYWORDS: Organizational chãos; Self regulation; Spirituality; Workplace.

\section{LA ESPIRITUALIDAD EN EL AMBIENTE DE TRABAJO COMO AGENTE DE AUTORREGULACIÓN DEL CAOS ORGANIZACIONAL}

RESUMEN: El presente estudio tuvo como objetivo reflejar cómo las organizaciones mientras cerebros, según la metáfora de Morgan (2002), pueden desarrollar la espiritualidad en el ambiente de trabajo como agente de autorregulación del caos organizacional contemporáneo. Considerando la necesidad contemporánea de las organizaciones en buscar soluciones para la disminución o eliminación de las dimensiones destructivas que la integran, el estudio se justifica como una posible respuesta a ese problema social. Para ello, se desarrolló un ensayo teórico utilizando como principales referencias las menciones teóricas de Morgan (2002) y Siqueira et al. (2014). Mientras ensayo, el estudio no tuvo como objetivo presentar conclusiones definitivas sobre el tema, sin embargo, las observaciones indican la posibilidad de que la espiritualidad en el ambiente de trabajo sea un instrumento de autorregulación del caos organizacional contemporáneo. De esa forma, esa y otras cuestiones presentadas en el estudio encuentran viabilidad para el desarrollo de futuras investigaciones empíricas para análisis de ese importante tema actual.

PALABRAS CLAVE: Ambiente de trabajo; Autorregulación; Caos organizacional; Espiritualidad.

\section{INTRODUÇÃO}

A complexidade e o caos que as organizações estão sujeitas no contexto contemporâneo de trabalho, pode ser fruto da ideia aperfeiçoada de Frederico o Grande. Frederico foi o percussor da engenharia de um exército, de forma que 
esse viesse a se tornar um mecanismo eficiente (MORGAN, 2002). No decorrer dos tempos, a ideia passou a ser uma realidade dos postos de trabalho mais diversos, como por exemplo, o escritório. Como resultado, observa-se na atualidade, a abertura para o caos no ambiente de trabalho, devido à desumanização que os funcionários passaram a estarem sujeitos em detrimento do alcance dos objetivos das organizações (MORGAN, 2002). Essa desumanização tem causado diversos malefícios aos trabalhadores, com destaque para as doenças psicossomáticas. No estudo proposto, essa dimensão perversa das organizações será abordada como uma situação de caos, devido o pressuposto que as organizações deveriam ter um papel de desenvolvimento humano e social, e não, uma possível autodestruição e uma possível desumanização dos seres humanos.

Nesse contexto organizacional, é que a espiritualidade no ambiente de trabalho (EAT) pode se apresentar como um agente de regulação ou diminuição do caos presente. Pesquisas têm apresentado os benefícios da prática da EAT e sua dimensão humanística (VERGARA; MOURA, 2012). Dessa forma, as menções de Gareth Morgan (2012) que explicam as organizações como máquinas e como cérebros, são viáveis para refletir na possibilidade da EAT ser um elemento de autorregulação do caos organizacional.

Para o estudo proposto será desenvolvido um ensaio teórico. Embora se considere a premissa de que não é possível esgotar a compreensão sobre a temática sugerida. Será analisado as considerações de diferentes autores, pois o ensaio teórico enquanto método científico, não busca estabelecer respostas afirmativas, mas suscitar reflexões que possibilitem a análise e conclusões por parte do leitor (BARROS, 2011; BERTERO, 2011; MENEGHETTI, 2011; POUPART et al., 2014).

A técnica é apropriada para os objetivos pretendidos, visto que se é necessário refletir a possibilidade da EAT ser um elemento de autoregulação do caos organizacional contemporâneo. Considerando que o ensaio teórico é um texto para discutir determinado tema, de relevância teórica e científica, com bases teóricas (BARROS, 2011; BERTERO, 2011; MENEGHETTI, 2011; POUPART et al., 2014), será abordado as considerações de Morgan (2012) e Siqueira et. al. (2014) de forma dialética e reflexiva.

O estudo se justifica pela necessidade contemporânea das organizações e seus membros, na busca pela diminuição ou eliminação das dimensões destrutivas dos contextos organizacionais. Essas dimensões são físicas, emocionais, ambientais e até espirituais, as quais influenciadas pela lógica mecanicista organizacional apresentam-se como um verdadeiro caos social.

As seções seguintes abordarão a reflexão proposta e apresentará a análise teórica sobre a origem do trabalho, a constituição do caos no ambiente de trabalho e a espiritualidade no ambiente de trabalho. Por fim, será analisado como 
a espiritualidade no ambiente de trabalho pode se tornar um agente de autorregulação do caos organizacionais.

\section{REVISÃO BIBLIOGRÁFICA}

\subsection{A origem do trabalho}

Pensar na origem do trabalho é pensar na origem da humanidade. Isso por que, desde os tempos primitivos o ser humano sempre trabalhou para a manutenção da vida. Considerando que esse sempre esteve sujeito aos fenômenos da natureza, o mínimo que ele poderia fazer era se defender (WEBER, 2013). Por isso, existe o consenso entre os pesquisadores e historiadores em classificar as primeiras atividades humanas em colheitas, caças, busca de abrigo e proteção contra os inimigos. Com isso, a definição de trabalho se configurou com uma perspectiva diferente da qual contemplamos hoje. Weber (2013) denominará o trabalho como a ação produtiva e criativa do ser humano, seja ela intelectual ou física.

O viver humano proporcionou a aquisição de conhecimento, de forma que esse passou a progredir em técnicas e ciência, gerando os primeiros meios de educação da humanidade, que consistia em transferir o conhecimento adquirido para os companheiros de comunidade, principalmente de trabalho (PEREIRA, 2012). Isso expressa o quanto as formas de trabalho, sejam elas nas atividades do lar, na agricultura, no desenvolvimento da comunidade, entre outras, eram grandes fomentadoras de conhecimento e progresso da humanidade.

Weber (2013) ainda esclarece, que o papel central do trabalho na história da humanidade e a aptidão humana para tais atividades, podem ser facilmente compreendidas não só pelo fato da necessidade humana, mas também pela característica homo faber do homem.

A palavra homo faber é de origem latina, na qual homo significa homem e faber significa fabricador ou criador. Conforme observa Weber (2013), o termo indica que o ser humano é um ser fabricante e criador, além de pensante e comunicador. Assim, como remete as histórias sobre a humanidade, desde o princípio, o ser humano é um ser provedor. Isso significa que o ser humano sempre identificou suas necessidades e trabalhou para supri-las. Dessa forma, a humanidade sempre conquistou sua provisão, produziu cultura e proporcionou o seu desenvolvimento através do trabalho, por ser um homo faber (WEBER, 2013).

O homo faber, ou o homem fabricador, traz consigo o conceito da vida humana capaz e criativa para produzir progresso técnico, científico, ético, moral e social, através do trabalho (WEBER, 2013). Não se pode negar os avanços que a humanidade obteve por meio do trabalho. Também não se pode negar os avanços que estão ocorrendo e ocorrerão no futuro. Isso, porque as ações criativas do 
homem vão sendo registradas no decorrer da história e aprimoradas. Assim, o conhecimento humano adquirido vai sendo aperfeiçoado e ampliado, resultando, consequentemente, em avanços e progressos. Portanto, as ferramentas, os recursos e o próprio produto final de um processo de fabricação ou produção, ganham eficiência, alta escala produtiva e melhorias. Nesse sentido é que ocorre o progresso técnico e científico. Esse progresso junto aos esforços filosóficos e sociológicos da humanidade proporciona o progresso ético, científico, moral e social da humanidade (WEBER, 2013).

\subsection{A constituição do caos no ambiente de trabalho}

No início o ser humano se organizava em comunidades e cada membro era um cooperador na manutenção da própria comunidade. Porém, quando os trabalhadores começaram a ficar ociosos, devido ao excesso de pessoas, estabeleceram-se outros trabalhos além da manutenção da comunidade. Esses trabalhos foram grandes empreendimentos e produção de recursos que proporcionaram poder social, como as armas e as empreitadas de guerra e dominação das comunidades vizinhas. Assim surgiram os grandes chefes, que criaram estados, sujeitaram pessoas e buscavam estabelecer relacionamentos com divindades com o objetivo de perpetuar o seu poder inclusive com a ajuda dos descendentes (PEREIRA, 2012).

A educação escolarizada surgiu com o estabelecimento do Estado, que era representado por personalidades junto aos seus familiares e amigos. Essa personalidade se destacava pela capacidade administrativa de organizar e captar as forças de trabalho, que lhe proporcionava poder econômico, social, político e até militar, pois esse era capaz de produzir construções e armas de guerra. Com isso se estabeleceu a divisão social do trabalho e a necessidade de uma instituição capaz de educar a sociedade para viver nesse novo estilo de vida (PEREIRA, 2012). É relevante observar que a educação era informal, com o objetivo de transferir conhecimento para a comunidade, para que o trabalho de manutenção e progresso da vida se estabelecesse nas atividades cotidianas.

Conforme explica Pereira (2012), as primeiras escolas não tinham o objetivo de educar toda a comunidade, que agora estava dividida entre proprietários e não proprietários, mas atendia primeiramente a classe de proprietários, para os quais era proporcionado uma educação em atividades intelectuais, na arte da palavra, nos exercícios físicos lúdicos ou militares, de forma que esses pudessem ter as condições de manterem seu poder econômico, político e militar. Posteriormente a classe de não proprietários passou a ser educada nas escolas, porém o ensino era sobre as técnicas nos processos de trabalhos, pois tratava-se de uma classe escrava e serviçal. Essas primeiras escolas surgiram no Egito Antigo.

Prosseguindo em sua vocação de homo faber, contudo em um novo 
contexto de trabalho, os avanços científicos e as tecnologias foram alterando as formas de produção. Assim, a história é marcada por formas de organização do trabalho sendo a escravagista, a feudal e a capitalista, essa última resultando na revolução industrial (VIZEU, 2010). Esses avanços maximizaram muitos efeitos e fenômenos sociais, como a educação, a produção e as formas de atuação no trabalho.

$\mathrm{Na}$ educação, além da necessidade de formalização dos meios para atender as demandas da sociedade, ocorreu o estabelecimento de níveis, de forma que, quando maior o grau de intelectualidade que era exigido na atividade profissional, maior deveria ser o nível de escolaridade que o indivíduo devia ter para atender os objetivos organizacionais (PEREIRA, 2012).

Nos processos produtivos, novos sistemas visando o maior aproveitamento e eficiência da mão de obra, resultaram em revoluções na forma industrial e alteração do perfil esperado do trabalhador. Desse modo, as formas de produção e organização do trabalho teorizadas por Taylor, Ford e Fayol, foram as grandes ferramentas propulsoras dessa revolução (VIZEU, 2010).

Já nas formas de atuação no trabalho, a complexidade, o constante aperfeiçoamento e a concorrência, ganharam e ganham destaque cada vez mais elevado com o foco no atendimento dos objetivos organizacionais. Consequentemente, o posicionamento submisso e reativo do trabalhador tem manifestado comportamentos destrutivos em todos os níveis hierárquicos da organização. $\mathrm{O}$ posicionamento submisso refere-se à pré-disposição do trabalhador em atuar em uma organização dada a sua necessidade e desejo. Já ao posicionamento reativo, refere-se às reações que se manifestam em meio ao ambiente de trabalho e aos estímulos que nele ocorrem. Assim, uma dimensão destrutiva tem se perpetuado no ambiente de trabalho, pois lidar com a complexidade e as constantes mudanças tem proporcionado espaços para aspectos desumanos. A esses aspectos, atribui-se o caos no ambiente de trabalho, visto que as organizações deveriam ter um papel de desenvolvimento humano e social, e não, autodestrutivo e desumano.

A complexidade e o caos que as organizações estão sujeitas no contexto contemporâneo de trabalho, pode ser fruto da ideia aperfeiçoada de Frederico o Grande. Frederico foi o percussor da engenharia de um exército, de forma que esse viesse a se tornar um mecanismo eficiente (MORGAN, 2002). Embora o objetivo primário fosse pertinente, os resultados de uma forma integral se mostram maléficos. Isso, por que o fato de se tornar o trabalhador em um mecanismo eficiente, geralmente despreza-se sua dimensão humana, suas limitações e sentimentos, provocando condições de stress, ansiedade, preocupação, desgaste, entre outros males emocionais e físicos. Com isso, o aumento do número de trabalhadores com doenças psicossomáticas pode ser o resultado do caos existente nos ambientes de trabalho. 
Neste contexto, entende-se que a espiritualidade pode se configurar em uma possibilidade que minimize os efeitos negativos deste ambiente de trabalho contemporâneo. Considerando que EAT pode contribuir para melhoria de fatores comunitários, as relações interpessoais e aspectos relacionados à dignidade humana, sua influência também pode contribuir para o desenvolvimento de um ambiente de trabalho mais harmonioso e alegre como se verá na seção a seguir.

\subsection{A espiritualidade no ambiente de trabalho}

Embora seja difícil encontrar uma definição universal para espiritualidade no trabalho (BARRETO; FEITOSA; BASTOS, 2014; SOUTO; REGO, 2006; REGO; CUNHA; SOUTO, 2007; SILVA; DURANTE; BISCOLI, 2015), para o presente artigo se adotou a definição de Siqueira et al. (2014) que compreende como sendo um estado mental positivo nutrido pelo indivíduo no ambiente organizacional, pela crença de sentido no trabalho e pertencimento entre as pessoas no ambiente de trabalho. Em resumo, pode-se definir espiritualidade no ambiente de trabalho como a ação profissional executada como propósito de vida e senso de comunidade (SIQUEIRA et al., 2014). Siqueira et al. (2014) explica que essa definição encontra fundamentação, pelo fato que o estado mental positivo nutrido pelo indivíduo no ambiente organizacional que irá configurar a espiritualidade, é composto por duas dimensões cognitivas, sendo: a crença de que o trabalho realizado oferece uma finalidade para a vida do indivíduo e de que há pertencimento entre as pessoas no ambiente de trabalho.

As pesquisas sobre espiritualidade nas organizações têm encontrado relevância ao se pensar nos problemas sociais que passam a fazer parte da rotina das organizações, relacionados com o individualismo, egoísmo, abuso de poder, tratamentos desumanos, stress, entre outros, e podem ser diminuídos por meio da prática de espiritualidade no ambiente de trabalho (BARRETO; FEITOSA; BASTOS, 2014; CARNEIRO; SERAFIM, 2015; SILVA; DURANTE; BISCOLI, 2015; VASCONCELOS, 2015; VERGARA; MOURA, 2012). Isso porque o fator comunitário, que a prática da espiritualidade ajuda desenvolver, pode melhorar as relações interpessoais e aspectos relacionados à dignidade humana, influenciando o desenvolvimento de um ambiente de trabalho mais harmonioso e alegre.

Assim, considerar que um indivíduo empregado, em sua maioria dedica cerca de 8 (oito) horas do seu dia ao trabalho, o ambiente de exercícios de suas atividades profissionais é altamente influenciador na maneira como o indivíduo retorna para as atividades fora da empresa, seja essa atividade com a família, amigos, vizinhos, ou a própria comunidade. Logo, um ambiente de trabalho que gera prejuízos emocionais, intelectuais, comportamentais, físicos e até espirituais, pode desencadear uma série de problemas sociais, os quais podem ser dimi- 
nuídos ou até evitados pela prática da espiritualidade no ambiente de trabalho. Entender a prática da espiritualidade presente nas organizações da atualidade e como essas surgiram pode ser o primeiro passo para que teorias mais abrangentes e aprofundadas relacionadas ao tema proposto contribua para o desenvolvimento teórico e a compreensão dos problemas locais (BERTERO, 2007; REGO; CUNHA; SOUTO, 2007; SIQUEIRA et al., 2014).

Vasconcelos (2015) ao apresentar reflexões sobre as organizações baseadas na espiritualidade discorre sobre os benefícios que esse tipo de organização pode proporcionar para os indivíduos e, consequentemente, para o planeta. Contudo, também apresenta os desafios que esse tipo de organização pode encontrar para se desenvolver em um mundo capitalista. Quanto a esses desafios, Barreto, Feitosa e Bastos (2014) compreendem que a espiritualidade organizacional deve estar subordinada ao lucro, ou seja, a racionalidade econômica.

\section{METODOLOGIA}

Para o desenvolvimento do estudo proposto foi realizado um ensaio teórico. Embora se considere a premissa de que não é possível esgotar a compreensão sobre a temática sugerida, foram analisadas as considerações de diferentes autores, pois o ensaio teórico enquanto método científico, não busca estabelecer respostas afirmativas, mas suscitar reflexões que possibilitem a análise e conclusões por parte do leitor (BARROS, 2011; BERTERO, 2011; MENEGHETTI, 2011; POUPART et al., 2014).

A técnica é apropriada para os objetivos pretendidos, visto que se é necessário refletir a possibilidade da EAT ser um elemento de autorregulação do caos organizacional contemporâneo. Considerando que o ensaio teórico é um texto para discutir determinado tema, de relevância teórica e científica, com bases teóricas (BARROS, 2011; BERTERO, 2011; MENEGHETTI, 2011; POUPART et al., 2014), será abordado as considerações de Morgan (2012) e Siqueira et. al. (2014) de forma dialética e reflexiva.

\section{ANÁLISE DOS RESULTADOS}

Morgan (2012) menciona em um de seus estudos, que as organizações podem ser vistas como cérebros. A metáfora sugere que as ações que as organizações praticam voluntariamente em suas atividades, se comparam com a atividade cerebral. Dentre esses comportamentos, Morgan (2012) destaca:

1. A capacidade de aprender com as experiências;

2. Portar flexibilidade, elasticidade e engenhosidade;

3. Capacidade de auto-organização, autoregulação e evolução diante dos 
desafios, por intermédio da inteligência;

4. Formado por vários compartimentos, porém representando um todo.

Demonstrando essas características principais do cérebro, Morgan (2012) resume que as organizações como cérebros, apresentam 3 (três) características: como cérebros processadores de informações, como sistemas complexos capazes de aprender e como sistemas holográficos que combinam características centralizadas e descentralizadas. Diante dos desafios organizacionais e o caos presente no dia a dia, como as organizações como cérebros, tem exercido sua capacidade de auto regulação nas questões destrutivas do ambiente de trabalho?

Pensar nos benefícios da EAT pode ser umas das ações organizacionais, como meio de auto regulação. Como menciona Siqueira et al. (2014), quando existe a prática da espiritualidade no ambiente de trabalho, desenvolvem-se duas dimensões, sendo o trabalho como propósito de vida e o senso de comunidade.

O trabalho como propósito de vida, constitui na convicção de que as tarefas realizadas no trabalho ou o próprio cargo contêm sentido para a vida e dão significado a ela (SIQUEIRA et al., 2014). Compreende-se uma situação onde o indivíduo considera que seu trabalho concede uma razão especial para sua vida.

O senso de comunidade refere-se às convicções de que as relações sociais dentro da organização constituem experiências assentadas em percepções de pertencimento (SIQUEIRA et al., 2014). Nesse caso, compreende uma situação na qual o indivíduo considera que no seu setor de trabalho existe espírito de solidariedade entre as pessoas. Dessa forma, é possível notar que o resultado da prática da EAT é oposto aos resultados da complexidade e dos mecanismos dos ambientes de trabalho contemporâneo, causadores do caos organizacional. Poderia de fato a EAT ser um agente de autorregulação do caos organizacional? Quanto a isso, pode se ainda observar a questão com referência ao Quadro 1.

Quadro 1: Resultados da EAT como agente de autorregulação do caos

\begin{tabular}{|l|l|l|}
\hline \multicolumn{1}{|c|}{$\begin{array}{c}\text { Contexto } \\
\text { Organizacional }\end{array}$} & \multicolumn{1}{|c|}{ Possível Caos } & \multicolumn{1}{|c|}{ Resultado da EAT } \\
\hline Vida pessoal & $\begin{array}{l}\text { A experiência profissional } \\
\text { sabota as realizações da } \\
\text { vida }\end{array}$ & $\begin{array}{l}\text { O trabalho é uma } \\
\text { realização pessoal }\end{array}$ \\
\hline $\begin{array}{l}\text { Relacionamentos } \\
\text { no ambiente de } \\
\text { trabalho }\end{array}$ & $\begin{array}{l}\text { Alta competitividade, } \\
\text { individualismo e disputa } \\
\text { para o sucesso profissional }\end{array}$ & $\begin{array}{l}\text { Sentimento de } \\
\text { pertencimento e trabalho } \\
\text { em equipe para o sucesso } \\
\text { mútuo }\end{array}$ \\
\hline $\begin{array}{l}\text { Sentimentos } \\
\text { presente no dia a dia }\end{array}$ & $\begin{array}{l}\text { Stress, disputa, egoísmo e } \\
\text { inimizades. }\end{array}$ & $\begin{array}{l}\text { Harmonia, cooperação e } \\
\text { senso de comunidade }\end{array}$ \\
\hline
\end{tabular}




\begin{tabular}{|l|l|l|}
\hline Foco do trabalho & $\begin{array}{l}\text { Maximização dos lucros e } \\
\text { ganhos materiais }\end{array}$ & $\begin{array}{l}\text { Sustentabilidade } \\
\text { financeira e } \\
\text { desenvolvimento humano }\end{array}$ \\
\hline
\end{tabular}

Fonte: Elaborado pelos autores (2017).

O Quadro 1 sugere uma possível autorregulação organizacional para a mecanização e alienação do trabalho. Contudo, o que levaria uma organização, ou seja, seus funcionários a buscarem a prática da espiritualidade como um meio de diminuir ou eliminar o caos organizacional?

Observa-se que a prática da espiritualidade no ambiente de trabalho, refere-se muito mais a virtudes comportamentais e valores pessoais, do que a religiosidade como normalmente é associado. A prática também encontra o desafio de equilibrar sua humanização com o retorno financeiro. Por isso, como menciona Barreto, Feitosa e Bastos (2014), a EAT deve estar subordinada a racionalidade capitalista para a sobrevivência da organização. Dessa forma, a maneira de se estabelecer a EAT, praticá-la e equilibrá-la, constitui o grande desafio das organizações contemporâneas. Assim, pode-se resumir a análise proposta com a seguinte ilustração:

Figura 1: Autorregulação do Caos Organizacional

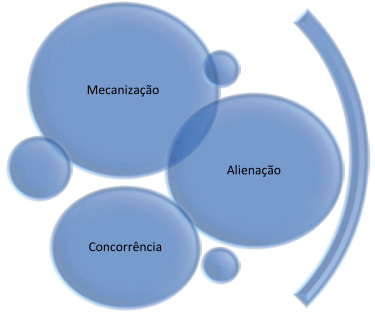

Caos OrganizacionaL (MORGAN, 2002)

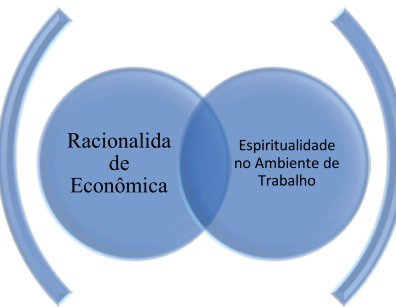

Autorregulação do caos organizacional (MORGAN, 2002; SIQUEIRA et. A1. 2014).

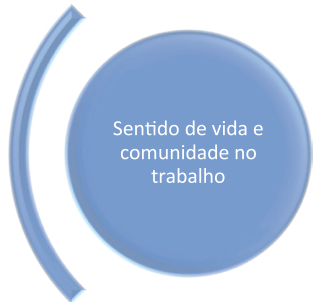

Espiritualidade Organizacional (SIQUEIRA et al., 2014)

Fonte: Elaborado pelos autores (2017).

Conclui-se que a autorregulação do caos organizacional é o resultado da interação da prática da EAT com a racionalidade econômica das organizações, de forma que os aspectos de mecanização, alienação e competitividade dos funcionários envolvidos em tais contextos, sejam diminuídos ou até eliminados. Esse resultado também remete a uma melhoria no ambiente de trabalho no que se refere à qualidade de vida, pois consequentemente, as motivações e o clima organizacional poderão ser alterados para uma condição considerada mais saudável e menos destrutiva. 


\section{CONSIDERAÇÕES FINAIS}

O caos organizacional presente no ambiente de trabalho contemporâneo em grande medida trata-se da perversidade humana que é estimulada pelas condições de trabalho. Assim, essa perversidade se manifesta em atitudes humanas conscientes ou inconscientes, provocando situações destrutivas e autodestrutivas para os indivíduos. A EAT apresenta-se como uma possível alternativa de minimização ou abolição dessa ação destrutiva. Contudo, o que levaria um indivíduo a optar pela prática da EAT ao invés de seguir um caminho de destruição? Essa questão se remete a consideração de que a EAT se trata de virtudes comportamentais e não somente de uma religiosidade como geralmente se é referido.

Quando se trata de religiosidade, a devoção a (s) divindade (s) geram comportamentos virtuosos como forma de submissão e respeito. É bem verdade que a religião promove a prática da espiritualidade em todos os contextos humanos, porém, é de possível consideração o fato de que a espiritualidade não é uma exclusividade da religião. Portanto, o desafio organizacional se estabelece em lidar com a lógica capitalista da sociedade e o estabelecimento da EAT. Porém, qual seria a vantagem do estabelecimento da EAT para as organizações, considerando que isso pode afetar os lucros organizacionais? Seria essa prática uma condição de lucro a longo prazo e consequentemente um investimento imediato da organização para que esse resultado seja alcançado?

Assim, o presente estudo, em forma de ensaio, apresentou a possível contribuição da EAT, e os questionamentos levantados do decorrer das explanações, sugere-se como foco de futuras pesquisas e reflexões na temática.

\section{REFERÊNCIAS}

BARRETO, T. F.; FEITOSA, M. G. G.; BASTOS, B. E. N. Espiritualidade no ambiente de trabalho no entendimento dos dirigentes e funcionários: Um estudo de múltiplos casos na Região Metropolitana do Recife. VIII Encontro de Estudos Organizacionais da ANPAD, Gramado/RS p. 1-16, mai. 2014.

BARROS, K. S. M. de. Réplica 1 - O que é um ensaio ? Revista de Administração Contemporânea, v. 15, n. 2, p. 333-337, mar./abr. 2011.

BERTERO, C. O. A Permanência da religião. GVexecutivo, v. 6, n. 6, nov.dez. 2007.

BERTERO, C. O. Réplica 2 - o que é um ensaio teórico? Réplica a Francis Kanashiro Meneghetti. Revista de Administração Contemporânea, v. 15, n. 2, p. 338-342, mar./abr. 2011. 
CARNEIRO, L. C.; SERAFIM, M. C. Uma Análise bibliométrica da relação entre ética e espiritualidade/religiosidade nas organizações. XL Encontro da ANPAD. Anais...Costa do Sauípe/BA: XL ANPAD, 2015

MENEGHETTI, F. K. O que é um ensaio-teórico? Revista de Administração Contemporânea, v. 15, n. 2, p. 320-332, mar./abr. 2011.

MORGAN, G. Imagens da organização. 2. ed. São Paulo: Atlas, 2002.

PEREIRA, M. de F. R. Trabalho e educação: uma perspectiva histórica. Curitiba: Intersaberes, 2012.

POUPART, J. et al. A pesquisa qualitativa: enfoques epistemológicos e metodológicos. 4. ed. Petrópolis, RJ: Vozes, 2014.

REGO, A.; CUNHA, M. P. E; SOUTO, S. Espiritualidade nas organizações e comprometimento organizacional. RAE-eletrônica, v. 6, n. 2, p. 1-27, jul./dez. 2007.

SILVA, A. C. C. da; DURANTE, D. G.; BISCOLI, F. R. V. Espiritualidade no ambiente de trabalho: estudo bibliométrico da produção acadêmica nacional 2010-2014. XVIII SemeAD - Semonários em Administração, p. 1-45, nov. 2015.

SIQUEIRA, M. M. M. et al. Espiritualidade no Trabalho. In: SIQUEIRA, M. M. M. (Ed.). Novas medidas do comportamento organizacional. Porto Alegre: Artmed, 2014. p. 157-171.

VASCONCELOS, A. F. The spiritually-based organization: a theoretical review and its potential role in the third millennium / A organização baseada na espiritualidade: uma revisão teórica e seu potencial papel no terceiro milênio. Cadernos EBAPE.BR, v. 13, n. 1, p. 183-205, jan./mar. 2015.

VERGARA, S. C.; MOURA, L. S. Práticas de espiritualidade na gestão de Pessoas. XXXVI Encontro da ANPAD. Anais... Riode Janeiro/RJ: set. 2012.

VIZEU, F. ( Re ) contando a Velha História : Reflexões sobre a Gênese do Management. RAC - Revista de Administração Contemporânea, v. 14, n. 5, p. 780-797, set./out. 2010 .

WEBER, O. J. Ética, educação e trabalho. Curitiba: Intersaberes, 2013. 